\title{
Secular trends and risk factors of overweight and obesity among Kuwaiti adults: National Nutrition Surveillance System data from 1998 to 2009
}

\author{
Faruk Ahmed ${ }^{1, *}$, Carol Waslien ${ }^{2}$, Mona A Al-Sumaie ${ }^{3}$ and Prasanna Prakash ${ }^{3}$ \\ ${ }^{1}$ School of Public Health, Griffith University, Gold Coast, QLD 4222, Australia: ${ }^{2}$ Department of Family Sciences, \\ College for Women, Kuwait University, Safat, Kuwait: ${ }^{3}$ Community Nutrition Promotion Department, Food and \\ Nutrition Administration, Ministry of Health, Kuwait
}

Submitted 29 June 2011: Accepted 15 December 2011: First published online 21 February 2012

\begin{abstract}
Objective: To determine trends in prevalence of overweight and obesity in Kuwaiti adults, and to examine their association with selected sociodemographic and lifestyle factors.

Design: Analysis of cross-sectional population survey data from the Kuwait National Nutrition Surveillance System.

Setting: Social and health facilities in Kuwait.

Subjects: Males ( $n 17$ 491) and females ( $n 21$ 120) aged 20-69 years attending registration for employment or pensions, or Hajj Pilgrimage health check-ups, or parents accompanying their children for immunization 1998 through 2009. Sociodemographic, lifestyle and anthropometric data were collected.

Results: Prevalence of BMI $\geq 25 \mathrm{~kg} / \mathrm{m}^{2}$ rose from $61 \cdot 8 \%$ and $59 \cdot 3 \%$ in females and males respectively, peaked in 2004-2005 (81.4\% and $79 \cdot 2 \%)$ and fell slightly in 2008-2009 (77.3\% and $77 \cdot 4 \%)$. Obesity prevalence in females exceeded males for all years and age groups; by 2009 , it had increased by $11.3 \%$ in males and $14.6 \%$ in females. Overweight and obesity prevalences in both genders increased until 2004-2005 but fell thereafter, with significant falls for females in 2008-2009. Logistic and linear regression analyses confirmed these temporal changes for both prevalence and BMI in both genders. The odds of obesity increased with age until the fifth decade for both genders and then declined significantly for males. Education level was negatively associated with obesity prevalence in females, while participation in leisure-time exercise was negatively associated with obesity prevalence in males.

Conclusions: Although the combined prevalence of overweight and obesity (BMI $\geq 25 \mathrm{~kg} / \mathrm{m}^{2}$ ) seemed to decrease from 2005 to 2009 among Kuwaiti adults, further research to clarify the identified confounders and continued monitoring are needed to confirm the decrease observed.
\end{abstract}

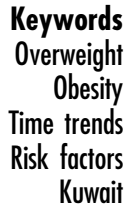

Prevalences of overweight and obesity have increased at epidemic rates across the world. In 2008, WHO estimated that 1.5 billion adults globally were overweight, 500 million of whom were obese ${ }^{(1)}$. The high level of obesity and overweight is a great public health concern as it is associated with a number of chronic diseases ${ }^{(2-6)}$. Recent estimates indicate that $44 \%$ of the diabetes burden and $23 \%$ of IHD are attributable to overweight and obesity ${ }^{(1)}$. In addition, $2 \cdot 8$ million adult deaths each year are attributable to overweight and obesity ${ }^{(1)}$.

The rapid increase in wealth of oil-rich countries of the Arabian Gulf has been associated with rapid increases in the prevalence of obesity, diabetes and CVD. These biological changes resulting from alterations in diet, physical activity and body composition are reported to be occurring at far greater speed and at earlier stages of economic and social development than in Western countries and may reflect unique issues related to changes in body composition or to genetic factors including the disease and obesity relationship ${ }^{(7)}$. Simultaneously, Westernization through media exposure that equates thinness with attractiveness, as well as increased awareness of the health risk of obesity, has led to disordered eating behaviour in some population sectors, particularly in young women ${ }^{(8)}$.

Kuwait instituted a National Nutrition Surveillance System (KNNS) in 1998 after nationwide surveys showed that the prevalences of obesity, diabetes and CVD were increasing at rates far beyond those of most countries ${ }^{(9-11)}$. A $22.7 \%$ increase in obesity prevalence was observed 
among Kuwaiti adults at primary health-care clinics between 1980-1981 and 1993-1994 ${ }^{(9)}$. A recent review of studies from the region reported positive trends in overweight and obesity throughout the Arab and Gulf States ${ }^{(10)}$ with Kuwait showing a continuation of the increase in 1994 overweight and obesity prevalence into 2006. A major limitation in that analysis was the ignoring of potential confounding factors such as differences in age distribution, lifestyle or education. The present study was carried out to determine 12-year trends in overweight and obesity during and after this period, and to examine factors that may have contributed to variation in prevalence in Kuwaiti adults.

\section{Materials and methods}

\section{Study population}

Data were collected as part of the KNSS for years 1998 through 2009. The Nutrition Administration of the Ministry of Health established the KNSS to continuously monitor the nutritional health status of the Kuwaiti population using a serial cross-sectional design. The analysis was restricted to adults aged 20 to 69 years who attended mandatory health examinations for registration for government employment or pensions ${ }^{(12)}$. All Kuwaiti citizens have virtually guaranteed employment and enjoy a retirement pension. According to the Public Authority for Civil Information, $80 \%$ of employed Kuwaiti males and females worked in the public sector in 2009. To ensure representative samples, data were also collected from attendees at mandatory Hajj Pilgrimage health check-ups and from parents accompanying children for mandatory immunizations at local health centres. Informed consent was sought from each participant before data were collected. Refusal rates were very low. The study was approved by the Ministry of Health, Kuwait.

Surveillance efforts began in 1998 with assessment of body weights and heights to estimate the prevalence of overweight and obesity by BMI, together with information on age, gender and education level. Education level was determined by asking participants whether they were illiterate, or had completed primary, intermediary, secondary, diploma, undergraduate or postgraduate levels. Subsequently, information on smoking and exercise were added in 2003. As Kuwaitis are generally engaged in office work that involves only sedentary activities and do little household work, physical activity was defined as deliberate non-work-related exercise outside the home such as walking, running, cycling or swimming. Those who smoked cigarettes, sheesha (water-pipe) and/or cigars at least once daily were defined as smokers.

\section{Data collection}

Body weight and height were measured in light clothing without shoes. Height was measured to the nearest $0 \cdot 1 \mathrm{~cm}$, using a stationary height board. Body weight was measured to the nearest $0 \cdot 1 \mathrm{~kg}$ using an electronic balance (Seca model 770). BMI was calculated from weight and height as weight $(\mathrm{kg}) /[\text { height }(\mathrm{m})]^{2}$.

\section{Statistical analysis}

Data were analysed using the SPSS for Windows statistical software package version 17 (SPSS Inc., Chicago, IL, USA). Frequency distribution of BMI was skewed towards higher values; therefore age-specific medians across all years of the study period were used for comparison and trend identification. Differences in BMI between males and females within age groups were compared with the Mann-Whitney $U$ test. Obesity and overweight were analysed as categorical variables, with the cut-off used to define overweight $\left(\mathrm{BMI}=25 \cdot 0-29 \cdot 9 \mathrm{~kg} / \mathrm{m}^{2}\right)$ and obesity $\left(\mathrm{BMI} \geq 30 \cdot 0 \mathrm{~kg} / \mathrm{m}^{2}\right.$ ) taken from $\mathrm{WHO}^{(13)}$. Participants were divided into groups, either on the basis of prior logical categories or to produce a sizeable number in each group. For age, participants were divided into five groups: 20-29, 30-39, 40-49, 50-59 and 60-69 years. For time trend, the 12-year period was divided into six 2-year periods (1998-1999, 2000-2001, 2002-2003, 2004-2005, 2006-2007 and 2008-2009). Participants' education level was classified into three levels: intermediary or lower, high school and diploma, and undergraduate and above. The $Z$ test was performed for males and females separately to detect differences in the prevalences of overweight and obesity between the subgroups for all factors (age group, time period, education level, smoking and exercise status).

Associations between BMI and study period were determined by multiple linear regression analysis using data stratified by 5-year time segments within each gender and controlling for age and education level. To show the time trend within age groups, data were stratified by age decade within each gender and controlled for age and education.

Trends in obesity and overweight prevalences were examined using multiple logistic regression analysis (enter method) within the six 2-year time periods for males and females separately after adjustment for age and education level. A second model was used to evaluate risk factors associated with overweight and obesity by combining all study years, with age group, education level, exercise and smoking status included as independent variables.

\section{Results}

A total of 17491 males and 21120 females were included in the analysis. Data on exercise were available for 10907 males and 12825 females and on smoking for 11491 males and 14035 females. The combined prevalence of overweight and obesity increased from 1998 to 2009 in both males (by 18.1\%) and females (by $15 \cdot 5 \%$; Fig. 1). 

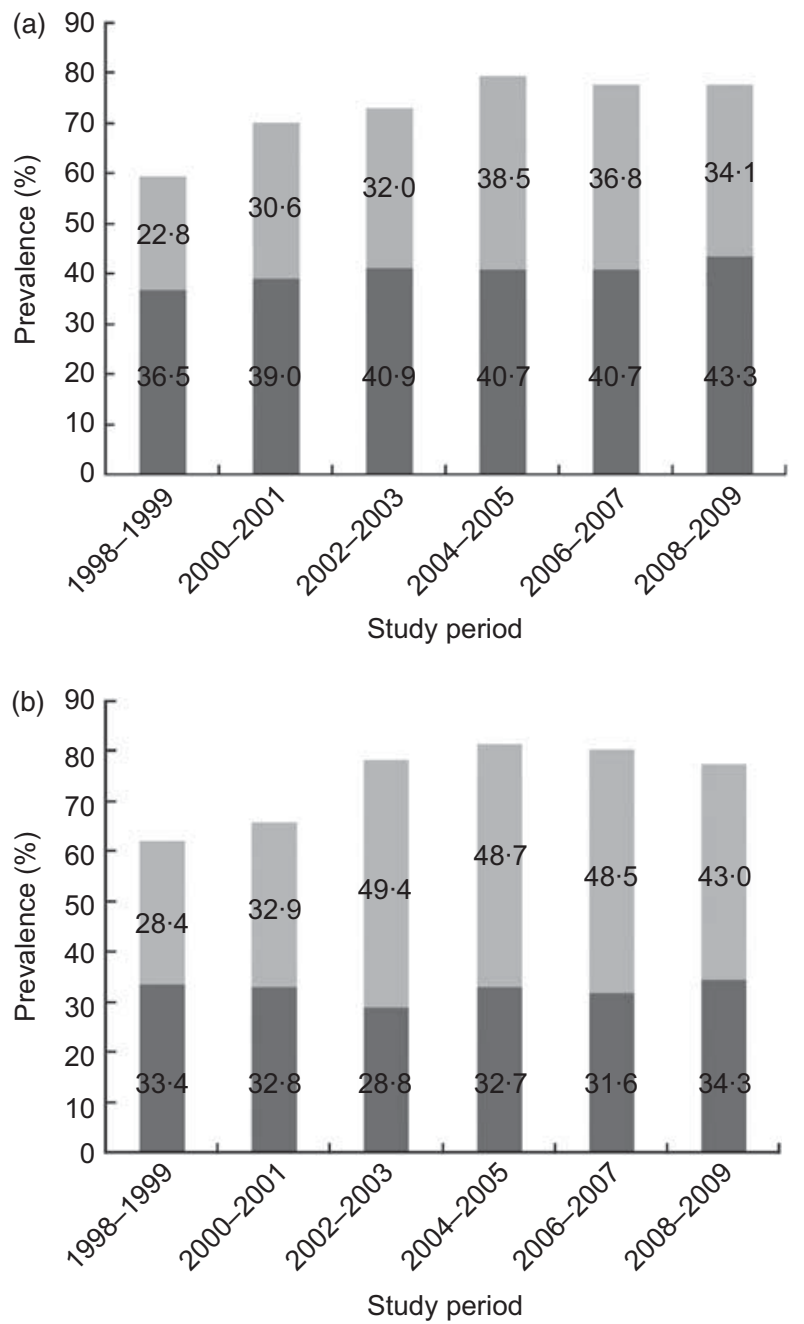

Fig. 1 Prevalence of overweight $(\square)$ and obesity $(\square)$ by study period in Kuwaiti males (a) and females (b) aged 20-69 years, National Nutrition Surveillance System data from 1998 to 2009

It reached a maximum in 2004-2005 and then declined slightly. In males, the obesity and overweight prevalences increased by $11.3 \%$ and $6.8 \%$, respectively, during the 12 years. Obesity reached a maximum $(38.5 \%)$ in 2004-2005 and then declined by $4 \cdot 4 \%$ in $2008-2009$, but overweight prevalence increased by $2 \cdot 6 \%$ from 2004-2005 to 2008-2009. In females, the obesity and overweight prevalences increased by $14.6 \%$ and $0.9 \%$, respectively, during the 12 years. Obesity reached a maximum $(49 \cdot 4 \%)$ in 2002-2003 and then declined by $6 \cdot 4 \%$ in $2008-2009$, while the overweight prevalence increased by $5.5 \%$ after 2002-2003. The obesity prevalence was higher in females throughout the 12 years, while the overweight prevalence was more often higher in males.

Age-specific median BMI and interquartile ranges were significantly higher for females than for males $(P=0 \cdot 001)$ in all age groups, except during the second decade (Fig. 2). For males, median BMI increased with age and reached a maximum at the fourth decade, decreasing

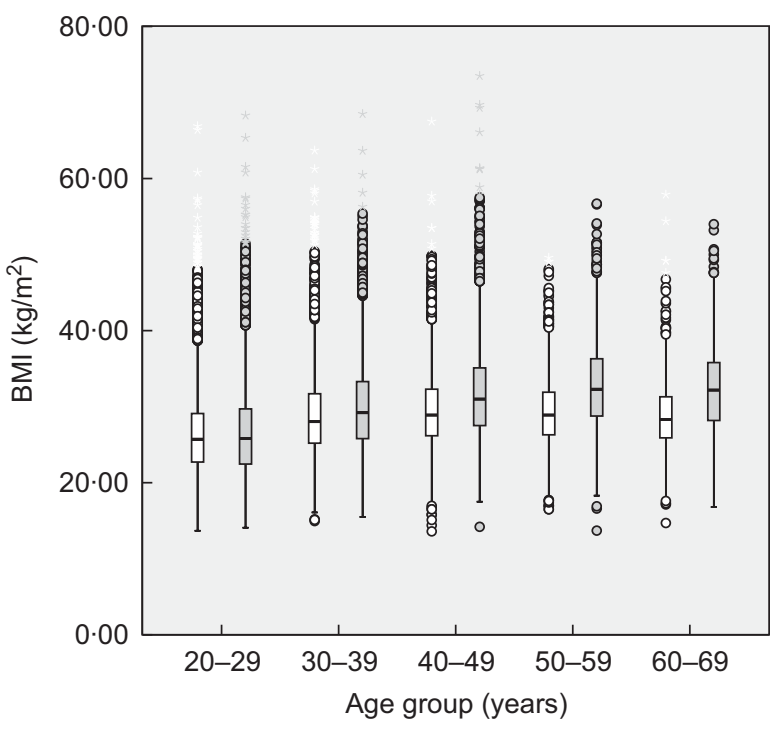

Fig. 2 Box plots for age-specific median BMI by sex ( $\square$, males; $\square$, females) across all years: Kuwaiti adults aged $20-69$ years, National Nutrition Surveillance System data from 1998 to 2009. Medians are shown as horizontal lines, boxes show interquartile ranges, circles show outlying values and stars show extreme values

significantly in the sixth decade. For females, median BMI increased with age until the fifth decade and then declined slightly.

Overweight prevalence increased significantly in males from $35.0 \%$ in the second age decade to $46.9 \%$ in the sixth (Table 1). Obesity prevalence also increased with age, reaching a maximum $(41.0 \%)$ in the fourth and fifth decades, decreasing by $7 \cdot 1 \%$ in the sixth. In females, overweight prevalence varied from $25 \cdot 3 \%$ to $35 \cdot 8 \%$ across age groups, with the highest prevalence in the third decade. Obesity prevalence increased sharply with age, reaching a maximum (67.8\%) in the fifth decade and decreasing by $5.0 \%$ in the sixth. Overall, the obesity rate was consistently higher in females than in males for all age groups.

Obesity prevalence decreased in both genders with increases in education level, while overweight prevalence increased with higher education level (Table 1). Males who exercised had a significantly lower prevalence of obesity than those who did not and male smokers had significantly lower prevalences of overweight and obesity than male non-smokers.

Linear regression models for BMI prediction using 5-year time segments within each gender, after adjusting for age and education, showed positive trends for year of study until 2001-2005 followed by increasingly negative trends for year of study until 2005-2009 in both genders (Table 2). The rate of these changes ranged from $+0 \cdot 355$ to $-0 \cdot 172 \mathrm{~kg} / \mathrm{m}^{2}$ per year for males and from $+0 \cdot 232$ to $-0 \cdot 192 \mathrm{~kg} / \mathrm{m}^{2}$ per year for females. Hence males gained more within the time period of greatest increase and lost less during the time of greatest decrease. 
Table 1 Sex-specific prevalences of overweight and obesity by selected sociodemographic and lifestyle factors in Kuwaiti adults aged 20-69 years, National Nutrition Surveillance System data from 1998 to 2009

\begin{tabular}{|c|c|c|c|c|c|c|}
\hline \multirow[b]{2}{*}{ Variable } & \multicolumn{3}{|c|}{ Males ( $n 17$ 491) } & \multicolumn{3}{|c|}{ Females (n 21 120) } \\
\hline & $n$ & $\begin{array}{l}\text { Overweight* } \\
(\%)\end{array}$ & $\begin{array}{l}\text { Obesity† } \\
\text { (\%) }\end{array}$ & $n$ & $\begin{array}{c}\text { Overweight* } \\
(\%)\end{array}$ & $\begin{array}{c}\text { Obesity } \dagger \\
(\%)\end{array}$ \\
\hline \multicolumn{7}{|l|}{ Age group (years) } \\
\hline $20-29$ & 6060 & $35 \cdot 0^{a}$ & $21 \cdot 5^{a}$ & 8810 & $32 \cdot 1^{a}$ & $23 \cdot 9^{a}$ \\
\hline 30-39 & 4216 & $41 \cdot 6^{\mathrm{b}}$ & $35 \cdot 2^{b}$ & 5413 & $35 \cdot 8^{\mathrm{b}}$ & $44 \cdot 5^{b}$ \\
\hline $40-49$ & 4033 & $42 \cdot 6^{\mathrm{bc}}$ & $41 \cdot 0^{\mathrm{c}}$ & 4228 & $31 \cdot 8^{a}$ & $57 \cdot 3^{\mathrm{C}}$ \\
\hline $50-59$ & 2290 & $44 \cdot 3^{\mathrm{c}}$ & $41 \cdot 0^{\mathrm{C}}$ & 2070 & $25 \cdot 3^{c}$ & $67 \cdot 8^{d}$ \\
\hline $60-69$ & 892 & $46 \cdot 9^{d}$ & $33.9^{b}$ & 599 & $30 \cdot 9^{a}$ & $62 \cdot 8^{\mathrm{e}}$ \\
\hline \multicolumn{7}{|l|}{ Education level } \\
\hline Intermediary or lower & 4152 & $38 \cdot 1^{a}$ & $33.9^{a}$ & 4946 & $25 \cdot 9^{a}$ & $61 \cdot 3^{a}$ \\
\hline High school \& diploma & 7735 & $39 \cdot 5^{a}$ & $33 \cdot 7^{\mathrm{a}}$ & 8429 & $32 \cdot 8^{\mathrm{b}}$ & $40 \cdot 9^{b}$ \\
\hline Undergraduate \& above & 5604 & $42 \cdot 7^{b}$ & $29 \cdot 6^{b}$ & 7745 & $35 \cdot 8^{c}$ & $28 \cdot 9^{c}$ \\
\hline \multicolumn{7}{|l|}{ Exercise } \\
\hline No & 6892 & $40 \cdot 2^{a}$ & $38 \cdot 1^{b}$ & 9649 & $31 \cdot 4^{a}$ & $48 \cdot 0^{a}$ \\
\hline Yes & 4015 & $43 \cdot 1^{b}$ & $30 \cdot 5^{a}$ & 3176 & $33 \cdot 2^{a}$ & $46 \cdot 3^{a}$ \\
\hline \multicolumn{7}{|l|}{ Smoking status } \\
\hline No & 7677 & $41 \cdot 9^{b}$ & $35 \cdot 6^{b}$ & 13410 & $32 \cdot 1^{a}$ & $46 \cdot 0^{\mathrm{a}}$ \\
\hline Yes & 3814 & $39 \cdot 4^{a}$ & $33 \cdot 4^{\mathrm{a}}$ & 625 & $29 \cdot 9^{a}$ & $53 \cdot 0^{b}$ \\
\hline
\end{tabular}

$n$, number of participants.

a,b,c,d,e Values within a column with unlike superscript letters were significantly different $(Z$ test; $P<0 \cdot 05)$.

${ }^{*}$ Cut-off for overweight: $\mathrm{BMI}=25 \cdot 0-29 \cdot 9 \mathrm{~kg} / \mathrm{m}^{2}$.

tCut-off for obesity: $\mathrm{BMI} \geq 30 \cdot 0 \mathrm{~kg} / \mathrm{m}^{2}$.

Table 2 Linear regression analysis for predicting BMI over time within each 5-year time segment and age group for Kuwaiti adults aged 20-69 years, National Nutrition Surveillance System data from 1998 to 2009

\begin{tabular}{|c|c|c|c|c|c|c|}
\hline & \multicolumn{3}{|c|}{ Males } & \multicolumn{3}{|c|}{ Females } \\
\hline & $n$ & $B^{\star}$ & $P$ value & $n$ & $B^{\star}$ & $P$ value \\
\hline \multicolumn{7}{|l|}{ Study period } \\
\hline 1998-2002 & 6894 & -0.006 & 0.068 & 8768 & -0.091 & 0.068 \\
\hline 1999-2003 & 7938 & $0 \cdot 214$ & 0.001 & 9030 & 0.144 & 0.002 \\
\hline 2000-2004 & 7300 & $0 \cdot 186$ & 0.001 & 8569 & $0 \cdot 160$ & 0.001 \\
\hline 2001-2005 & 6278 & 0.355 & 0.001 & 8175 & $0 \cdot 232$ & 0.001 \\
\hline 2002-2006 & 6983 & 0.307 & 0.001 & 8630 & 0.021 & 0.664 \\
\hline 2003-2007 & 7954 & 0.070 & 0.084 & 9162 & -0.022 & 0.608 \\
\hline 2004-2008 & 7444 & -0.099 & 0.030 & 8617 & -0.069 & $0 \cdot 125$ \\
\hline 2005-2009 & 7556 & $-0 \cdot 172$ & 0.001 & 8333 & -0.192 & 0.001 \\
\hline All & 17491 & $0 \cdot 121$ & 0.001 & 21120 & 0.046 & 0.001 \\
\hline \multicolumn{7}{|c|}{ Age group (years) } \\
\hline $20-29$ & 6060 & $0 \cdot 141$ & 0.001 & 8810 & 0.075 & 0.001 \\
\hline $30-39$ & 4216 & $0 \cdot 106$ & 0.001 & 5413 & 0.022 & 0.333 \\
\hline $40-49$ & 4033 & 0.029 & 0.243 & 4228 & -0.026 & 0.403 \\
\hline $50-59$ & 2290 & -0.010 & 0.748 & 2070 & -0.075 & $0 \cdot 136$ \\
\hline $60-69$ & 892 & $0 \cdot 107$ & 0.090 & 599 & -0.137 & 0.013 \\
\hline All & 17491 & $0 \cdot 121$ & 0.001 & 21120 & 0.046 & 0.001 \\
\hline
\end{tabular}

$n$, number of participants; $B$, slope of the regression line.

${ }^{*}$ Adjusted for age and education level.

Logistic regression modelling was used to determine temporal trends in prevalences of obesity and overweight for each 2-year span compared with 1998-1999 after adjustment for age and education level (Table 3). The odds of obesity and overweight increased in both males and females in successive 2-year time periods until 2004-2005, and then decreased. However, the odds of obesity and overweight in males were still significantly higher in 2008-2009 than in 1998-1999, while in females the odds for obesity decreased significantly from 2004-2005 (OR =1.39; 95\% CI 1.21, 1.59) to 2008-2009
$(\mathrm{OR}=1 \cdot 03 ; 95 \% \mathrm{CI} 0 \cdot 90,1 \cdot 17)$, a rate that did not differ from 1998-1999.

A second logistic regression model showed that age was independently associated with overweight and obesity prevalences (Table 4). Compared with the second age decade, the likelihood of obesity in males increased significantly until the fifth decade, then fell significantly in the sixth. Although the trend for overweight between age groups was similar, the decline from the fifth to the sixth decade was not significant. Compared with the second decade, the odds of overweight and obesity in females 
also increased significantly with age. The highest odds for obesity were observed in the fifth decade, falling in the sixth.

In males, the odds of overweight or obesity increased significantly with level of education (Table 4). In contrast, the likelihood of both overweight and obesity decreased with level of education in females, except for overweight in high school and diploma graduates. Among males, those who exercised were significantly less likely to be obese and those who smoked were significantly less likely to be overweight.

\section{Discussion}

As expected, there were significant positive temporal changes in unadjusted prevalences of overweight and

Table 3 Sex-specific odds ratios for the prevalence of overweight and obesity according to study period in Kuwaiti adults aged 20-69 years, National Nutrition Surveillance System data from 1998 to 2009

\begin{tabular}{|c|c|c|c|c|}
\hline & \multicolumn{2}{|c|}{ Overweight } & \multicolumn{2}{|c|}{ Obesity } \\
\hline & $\mathrm{OR}^{*}$ & $95 \% \mathrm{Cl}$ & $\mathrm{OR}^{*}$ & $95 \% \mathrm{Cl}$ \\
\hline \multicolumn{5}{|l|}{ Male } \\
\hline \multicolumn{5}{|l|}{ Study period } \\
\hline 1998-1999 & $1 \cdot 00$ & - & $1 \cdot 00$ & - \\
\hline $2000-2001$ & 0.98 & $0 \cdot 86,1 \cdot 11$ & 1.05 & $0.91,1.21$ \\
\hline $2002-2003$ & $1 \cdot 19$ & $1 \cdot 04,1 \cdot 35$ & $1 \cdot 27$ & $1 \cdot 10,1 \cdot 47$ \\
\hline $2004-2005$ & $1 \cdot 41$ & $1.23,1.63$ & 1.83 & $1 \cdot 57,2 \cdot 13$ \\
\hline $2006-2007$ & $1 \cdot 26$ & $1 \cdot 10,1 \cdot 44$ & 1.51 & $1 \cdot 31,1 \cdot 75$ \\
\hline 2008-2009 & $1 \cdot 35$ & $1 \cdot 18,1.55$ & $1 \cdot 46$ & $1 \cdot 26,1 \cdot 70$ \\
\hline \multicolumn{5}{|l|}{ Female } \\
\hline \multicolumn{5}{|l|}{ Study period } \\
\hline 1998-1999 & 1.00 & - & 1.00 & - \\
\hline 2000-2001 & 0.96 & $0.86,1.08$ & 0.90 & $0.80,1.02$ \\
\hline 2002-2003 & 1.05 & $0.93,1.19$ & $1 \cdot 28$ & $1 \cdot 12,1 \cdot 46$ \\
\hline 2004-2005 & $1 \cdot 26$ & $1 \cdot 11,1 \cdot 44$ & 1.39 & $1.21,1.59$ \\
\hline 2006-2007 & $1 \cdot 12$ & $0.98,1.27$ & $1 \cdot 32$ & $1 \cdot 16,1 \cdot 50$ \\
\hline 2008-2009 & 1.08 & $0.95,1.22$ & 1.03 & $0.90,1.17$ \\
\hline
\end{tabular}

*Adjusted for age and education level. obesity in the 12 years since 1998 in both Kuwaiti males and females. The combined prevalences of overweight and obesity in 2008-2009 of males and females were similar and alarmingly high ( $77 \%$ ), but obesity prevalence was significantly higher in females and overweight prevalence higher in males across all age decades and time periods. Increases in obesity prevalence have been reported for all Gulf countries ${ }^{(10)}$. A similar gender differential has also been reported in other studies in the Arab Gulf region ${ }^{(10,14)}$. Further, we found that the prevalence and odds of obesity as well as BMI increased with age until the fifth decade in both males and females and then declined, similar to age-related changes reported in Saudis ${ }^{(15)}$ and Iranians ${ }^{(16)}$.

Stratification by gender and adjustment for age and education in a logistic model showed that overweight and obesity prevalences in both males and females increased until 2004-2005, as predicted in the unadjusted frequency results, but rates of both fell thereafter, with a significant fall in 2008-2009 for females. Similarly, linear regression for BMI prediction using data stratified by gender and 5-year time segments showed only time periods between 1999 and 2006 were significantly positive for males and periods between 1999 and 2005 for females, while the two periods (2004-2008 and 2005-2009) for the males and 2005-2009 for females showed a negative annual change in BMI. Hence both linear and logistic regression showed an upward temporal trend until 2004-2006 followed by a downward trend until 2009. These trends resulted in a gain of $1.78 \mathrm{~kg} / \mathrm{m}^{2}$ between 2001 and 2005 and a loss of $0.86 \mathrm{~kg} / \mathrm{m}^{2}$ between 2005 and 2009 for males, but a smaller gain of $1 \cdot 16 \mathrm{~kg} / \mathrm{m}^{2}$ between 2001 and 2005 and larger loss of $0.96 \mathrm{~kg} / \mathrm{m}^{2}$ between 2005 and 2009 for females. Over the entire 12 years the gain was $0 \cdot 121 \mathrm{~kg} / \mathrm{m}^{2}$ per year in males and $0 \cdot 046 \mathrm{~kg} / \mathrm{m}^{2}$ per year

Table 4 Sex-specific odds ratios for the prevalence of overweight and obesity according to selected sociodemographic and lifestyle factors in Kuwaiti adults aged 20-69 years, National Nutrition Surveillance System data from 1998 to 2009

\begin{tabular}{|c|c|c|c|c|c|c|c|c|}
\hline & \multicolumn{4}{|c|}{ Males } & \multicolumn{4}{|c|}{ Females } \\
\hline & \multicolumn{2}{|c|}{ Overweight } & \multicolumn{2}{|c|}{ Obesity } & \multicolumn{2}{|c|}{ Overweight } & \multicolumn{2}{|c|}{ Obesity } \\
\hline & OR & $95 \% \mathrm{Cl}$ & OR & $95 \% \mathrm{Cl}$ & OR & $95 \% \mathrm{Cl}$ & OR & $95 \% \mathrm{Cl}$ \\
\hline \multicolumn{9}{|l|}{ Age (years) } \\
\hline $20-29$ & $1 \cdot 00$ & - & $1 \cdot 00$ & - & $1 \cdot 00$ & - & 1.00 & - \\
\hline $30-39$ & 2.05 & $1 \cdot 80,2 \cdot 33$ & $2 \cdot 61$ & $2 \cdot 27,3 \cdot 00$ & $2 \cdot 41$ & $2 \cdot 13,2 \cdot 73$ & $3 \cdot 72$ & $3 \cdot 28,4 \cdot 22$ \\
\hline $40-49$ & $2 \cdot 68$ & $2 \cdot 33,3.08$ & $3 \cdot 84$ & $3 \cdot 32,4 \cdot 44$ & 3.57 & $3 \cdot 09,4 \cdot 12$ & $7 \cdot 69$ & $6 \cdot 67,8 \cdot 87$ \\
\hline $50-59$ & $3 \cdot 15$ & $2 \cdot 67,3 \cdot 72$ & $4 \cdot 24$ & $3.57,5.04$ & $4 \cdot 68$ & $3 \cdot 75,5 \cdot 84$ & $12 \cdot 11$ & $9 \cdot 80,14 \cdot 96$ \\
\hline $60-69$ & $2 \cdot 69$ & $2 \cdot 17,3 \cdot 34$ & $2 \cdot 81$ & $2 \cdot 23,3.53$ & $5 \cdot 52$ & $3 \cdot 76,8 \cdot 11$ & $8 \cdot 54$ & $5 \cdot 91,12 \cdot 35$ \\
\hline \multicolumn{9}{|l|}{ Education level } \\
\hline Intermediary or lower & 1.00 & - & 1.00 & - & 1.00 & - & $1 \cdot 00$ & - \\
\hline High school \& diploma & $1 \cdot 30$ & $1 \cdot 15,1 \cdot 48$ & $1 \cdot 40$ & $1.23,1.59$ & 0.97 & $0 \cdot 83,1 \cdot 13$ & 0.57 & $0.50,0.66$ \\
\hline Undergraduate \& above & 1.45 & $1 \cdot 26,1 \cdot 66$ & $1 \cdot 28$ & $1 \cdot 11,1 \cdot 48$ & $0 \cdot 76$ & $0.65,0.89$ & $0 \cdot 31$ & $0.27,0.36$ \\
\hline \multicolumn{9}{|l|}{ Exercise } \\
\hline No & $1 \cdot 00$ & - & $1 \cdot 00$ & - & 1.00 & - & $1 \cdot 00$ & - \\
\hline Yes & 0.96 & $0.87,1.06$ & 0.74 & $0.66,0.82$ & 1.05 & $0.93,1 \cdot 18$ & 0.97 & $0 \cdot 86,1 \cdot 10$ \\
\hline \multicolumn{9}{|l|}{ Smoking } \\
\hline No & 1.00 & - & 1.00 & - & 1.00 & - & $1 \cdot 00$ & - \\
\hline Yes & 0.87 & $0.78,0.97$ & 0.90 & $0.81,1.01$ & 1.00 & $0.78,1 \cdot 30$ & $1 \cdot 06$ & $0 \cdot 82,1 \cdot 36$ \\
\hline
\end{tabular}


in females, for an average of $0.084 \mathrm{~kg} / \mathrm{m}^{2}$ per year. Higher gains in BMI $\left(0 \cdot 18 \mathrm{~kg} / \mathrm{m}^{2}\right.$ per year $)$ have been reported from surveillance data in Iran covering $1999-2007^{(17)}$, but with lower prevalence of overweight and obesity, possibility reflecting an early stage in the economic transition.

Further, linear regression analysis of data stratified by gender and age decade revealed a positive temporal trend for both genders that was significant only for the second and third decades for males and the second decade for females. Longitudinal studies in Iran have also shown that males in the second decade have the highest rate of increase of obesity prevalence ${ }^{(18)}$. The temporal increase in BMI of young females suggests that Western ideals for thinness and better appearance or concerns for a healthy body weight have not had a strong influence among the young Kuwaiti females within this time period, unlike reports coming from Lebanon ${ }^{(19)}$ and Qatar ${ }^{(8)}$.

In the present study, we also identified factors that are independently associated with overweight and obesity using gender-stratified logistic regression modelling. Although BMI is a well accepted indicator for overweight and obesity for national surveillance and comparison of international data ${ }^{(20)}$, and is highly correlated with percentage of body fat ${ }^{(21)}$, it does not distinguish between lean tissue and adiposity. For this, waist circumference is known to be a better indicator ${ }^{(21)}$, but is very difficult to determine in this population (modesty, clothing style) and therefore is not collected throughout the region. As a result, obesity prevalence estimates from the present study should be interpreted with caution.

The likelihood of obesity increased with age until the fifth decade for both males and females, and then declined significantly for males. Similar results have also been reported in Iranian populations ${ }^{(16)}$; the prevalence of obesity increased in both males and females until the sixth decade and then decreased. It was also found that females exceeded males in obesity prevalence across all age groups. Several factors could be responsible for this decrease with age: older people may adhere to traditional lifestyles that reduce obesity, people who were most obese died young from obesity-related illnesses, and/or subclinical illnesses reducing appetite. However, we do not have information to support any of these factors.

Gender differences in the effect of level of education, with highly educated females having lower odds for obesity or overweight while highly educated males had higher odds, cannot be entirely explained with this data set. Both studies in $\operatorname{Iran}^{(16)}$ and from 1993-1994 in Kuwait ${ }^{(9)}$ noted an inverse relationship between the likelihood of obesity and level of education for both genders that was most pronounced for university graduates.

Only in males, smoking was significantly negatively associated with the prevalence of overweight (although not with obesity). This stronger association of smoking in males might be explained by the higher intensity of smoking by Kuwaiti males ${ }^{(22)}$. Tobacco use is known to be associated with appetite suppression ${ }^{(23)}$ and previous studies have also reported a lower BMI in smokers ${ }^{(24)}$. However, the higher waist-to-hip ratio in smokers suggests smokers may have a metabolically adverse fat distribution profile ${ }^{(25)}$. Males who exercised were significantly less likely to be obese. Kuwaitis who participate in even moderate exercise have been shown to have delayed weight gain with age ${ }^{(26)}$. Further, the differential effect of exercise in males and females could be due the more vigorous exercise levels of Kuwaiti males ${ }^{(27)}$. Earlier studies in Kuwait have suggested that increased consumption of foods rich in fat and energy and sedentary lifestyles were responsible for the sharp rise of obesity ${ }^{(28,29)}$. Unfortunately, neither in the present study nor any other study in Kuwait has information on recent food consumption or exercise patterns of the population been gathered, making it difficult to explain the apparent downward trend in the obesity prevalence in recent years especially among older females.

It is noteworthy that in the present study we did stratification of data by age and year of study, which might reduce the likelihood of a significant effect in a subset due to a relatively smaller group size. However, there are distinct advantages to stratification since confounding variables may be affecting one subset more than others and stratification can pinpoint these differences. It certainly is important to identify confounders/related factors for the older subset (presence of disease, treatment of disease) that could account for the difference in time trend, just as it is important to determine what has contributed to the continued increase in obesity of those in their twenties. These confounders are likely to be different for each age group.

While efforts were made to obtain representative samples, the KNSS uses a convenience sampling and thus may not be representative of the wider population. Nevertheless, it is a strength of our study that it included a nationwide sample of more than 38000 individuals from an adult population of approximately 600000 and it is unlikely that the situation will be different from what is reported here.

\section{Conclusions}

A temporal increase in obesity occurred in Kuwaiti adults between 1998 and 2009 that was smaller than has been frequently reported for this region. It reflected a composite trend involving specific time period, age group, gender, and education level and lifestyle variables. Although a positive trend did occur for both genders, it did not occur in each age decade or every 5 -year time period; nor was the trend affected in the same manner for each gender by education level, smoking or exercise. However, given the cross-sectional nature of the study, no causal relationship of sociodemographic and lifestyle 
factors with overweight and obesity prevalence can be established. Further studies are needed including measurements of intensity and duration of exercise, smoking and diet to confirm possible trends in prevalence of overweight and obesity in relation to factors affecting them.

\section{Acknowledgements}

This research received no specific grant from any funding agency in the public, commercial or not-for-profit sectors. The authors declare they have no conflict of interest. F.A. and C.W. took the lead in the study concept and analysis and wrote the manuscript. M.A.A.-S. provided guidance on data collection and contributed in writing. P.P. was responsible for data management and cleaning. All authors read and approved the final manuscript.

\section{References}

1. World Health Organization (2011) Fact Sheet: Obesity and Overweight. Geneva: WHO; available at http:// www.who.int/mediacentre/factsheets/fs11/en/print.html

2. Hubert HB, Feinleib M, McNamara PM et al. (1983) Obesity as an independent risk factor for cardiovascular disease: a 26-year follow-up of participants in the Framingham Heart Study. Circulation 67, 968-977.

3. Chan JM, Rimm EB, Colditz GA et al. (1994) Obesity, fat distribution, and weight gain as risk factors for clinical diabetes in men. Diabetes Care 17, 961-969.

4. Wannamethee SG, Shaper AG \& Walker M (2005) Overweight and obesity and weight changes in middle aged men: impact on cardiovascular disease and diabetes. J Epidemiol Community Health 59, 134-139.

5. Nguyen NT, Magno CP, Lane KT et al. (2008) Association of hypertension, diabetes, dyslipidemia and metabolic syndrome with obesity: findings from National Health and Nutrition Examination Survey 1999-2004. J Am Coll Surg 207, 928-934.

6. Yang P, Zhou Y, Chen B et al. (2009) Overweight, obesity and gastric cancer risk: results from meta-analysis of cohort studies. Eur J Cancer 45, 2867-2873.

7. Popkin BM (2002) The shift in stages of the nutrition transition in the developing world differs from past experience! Public Health Nutr 5, 205-214.

8. Bener A \& Tewfik I (2006) Prevalence of overweight and obesity and associated psychological problems in Qatari's female population. Obes Rev 7, 139-145.

9. Al-Isa AN (1997) Body mass index and prevalence of obesity changes among Kuwaitis. Eur J Clin Nutr 51, 743-749.

10. Ng SW, Zaghloul S, Ali HI et al. (2011) The prevalence and trends of overweight, obesity and nutrition-related noncommunicable disease in Arabian Gulf States. Obes Rev 12, $1-13$.

11. Al-Rashdan I \& Al Nesef Y (2010) Prevalence of overweight, obesity and metabolic syndrome among adult
Kuwaitis: results from community-based national survey. Angiology 61, 42-48.

12. Jackson RT, Al-Mousa Z, Al-Kaqua M et al. (2002) Multiple coronary risk factors in healthy older Kuwait males. Eur J Clin Nutr 56, 709-714.

13. World Health Organization (2000) Obesity: Preventing and Managing the Global Epidemic. WHO Technical Report Series no. 894. Geneva: WHO.

14. Bagchi K (2008) Nutrition in the Eastern Mediterranean Region of the World Health Organization. East Mediterr Health J 14, Suppl., S107-S113.

15. Al-Nozha MM, Al-Mazrou YY, Al-Maatouq MA et al. (2005) Obesity in Saudi Arabia. Saudi Med J 26, 824-829.

16. Hajian-Tilaki KO \& Heidari B (2006) Prevalence of obesity, central obesity and the associated factors in urban population aged $20-70$ years, in the north of Iran: a population-based study and regression analysis. Obes $\operatorname{Rev} \mathbf{8}, 3-10$.

17. Esteghamati A, Khalilzadeh O, Mohammad K et al. (2006) Secular trends of obesity in Iran between 1999 and 2007: National Surveys of Risk Factors of Non-Communicable Diseases. Metab Synd Relat Disord 8, 209-213.

18. Hosseinpanah F, Barzin M, Eskandary PS et al. (2009) Trends of obesity and abdominal obesity in Tehranian adults: a cohort study. BMC Public Health 9, 426.

19. Afifi-Soweid RA, Kteily MBN \& Shediac-Rizkallah MC (2002) Preoccupation with weight and disordered eating behaviours of entering at a university of Lebanon. Int J Eat Disord 32, 52-57.

20. World Health Organization (1995) Physical Status: The Use and Interpretation of Anthropometry. WHO Technical Report Series no. 854. Geneva: WHO.

21. Flegal KM, Shepherd JA, Looker AC et al. (2009) Comparisons of percentage of body fat, body mass index, waist circumference, and waist-stature ratio in adults. Am J Clin Nutr 89, 500-508.

22. Memon A, Moody PM, Thattaruparambil N et al. (2000) Epidemiology of smoking among Kuwaiti adults: prevalence, characteristics and attitudes. Bull World Health Organ 78, 1306-1315.

23. Gatley I (2003) Tobacco: A Cultural History of How an Exotic Plant Seduced Civilization, p. 38. New York: Grove Press.

24. Perkins KA (1993) Weight gain following smoking cessation. J Consult Clin Psychol 61, 768-777.

25. Jee SH, Lee SY, Nam CM et al. (2002) Effect of smoking on the paradox of high waist-to-hip ratio and low body mass index. Obes Res 10, 891-895.

26. Ramadan J \& Barac-Nicto M (2001) Low frequency physical activity insufficient for aerobic conditioning is associated with lower body fat than sedentary conditions. Nutrition 17, 225-229.

27. Mabry RM, Reeves MM, Eakin EG et al. (2010) Evidence of physical activity participation among men and women in the countries of the Gulf Cooperation Council: a review. Obes Rev 11, 457-464.

28. Al-Moussa Z (1996) Nutrition related chronic diseases in Kuwait. In Diet-Related Non-Communicable Diseases in the Arab Countries of the Gulf, pp. 46-57 [AO Musaiger and SS Miladi, editors]. Cairo: FAO Regional Office for the Near East.

29. Al-Isa AN (1999) Dietary and socio-economic factors associated with obesity among Kuwaiti college men. BrJ Nutr 82, 369-374. 